\title{
Protein kinase clk/STY is differentially regulated during erythroleukemia cell differentiation: a bias toward the skipped splice variant characterizes postcommitment stages
}

\author{
Ana GARCÍA-SACRISTÁN", María J. FERnÁNDEZ-NESTOSA, Pablo HERnÁNDEZ, Jorge B. \\ SCHVARTZMAN, Dora B. KRIMER*
}

Department of Cell and Developmental Biology, Centro de Investigaciones Biológicas, Consejo Superior de Investigaciones Cientificas, Ramiro de Maeztu 9, Madrid 28040, Spain

\begin{abstract}
$\mathrm{Clk} / \mathrm{STY}$ is a LAMMER protein kinase capable to phosphorylate serine/arginine-rich (SR) proteins that modulate premRNA splicing. Clk/STY alternative splicing generates transcripts encoding a full-length kinase and a truncated catalytically inactive protein. Here we showed that clk/STY, as well as other members of the family (e.g. clk2, clk3 and clk4), are up-regulated during HMBA-induced erythroleukemia cell differentiation. mRNAs coding for the full-length and the truncated forms were responsible for the overall increased expression. In clk/STY, however, a switch was observed for the ratio of the two alternative spliced products. In undifferentiated cells the full-length transcript was more abundant whereas the transcript encoding for the truncated form predominated at latter stages of differentiation. Surprisingly, overexpression of clk/STY did not alter the splicing switch upon differentiation in MEL cells. These results suggest that clk/STY might contribute to control erythroid differentiation by a mechanism that implicates a balance between these two isoforms.
\end{abstract}

Keywords: clk/STY, LAMMER kinase, alternative splicing, erythroleukemia cells.

\section{INTRODUCTION}

Clk/STY (cdc-like-kinase, also known as Clk1) is a protein kinase that was identified while searching for tyrosine kinases involved in mammalian cell cycle regulation, differentiation programs and other cellular responses [13]. What clearly differentiates clk/STY from other kinases is a dual-specificity to phosphorylate tyrosine as well as serine-threonine residues $[1,2,4]$. Clk/STY is considered an important member of the LAMMER subfamily of protein kinases on behalf of a conserved amino acid motif reading "EHLAMMERILG", that is found at the catalytic subdomain X [5]. Members of the LAMMER subfamily occur in a variety of organisms from yeast to human [5-11], showing a high degree of conservation in

*Correspondence: Dora B. KRIMER

Tel: +34-918-373-112×4238;

E-mail: dbkrimer@cib.csic.es

"Present address: Institute of Molecular Medicine, 1649-028, Lisbon Medical School, Lisbon Portugal those domains that are essential for phosphotransfer and substrate recognition [12]. Furthermore, the ability of several LAMMER kinases to modulate splicing could indicate a common functional role [13-16].

$\mathrm{Clk} / \mathrm{STY}$ is implicated in the regulation of constitutive and alternative splicing through interactions with serine/ arginine (SR) rich proteins. In a yeast two-hybrid screen, Colwill and co-workers identified several RNA-binding proteins, all members of the SR family of splicing factors [17]. It was also shown that clk/STY phosphorylates SR proteins and that the phosphorylation status influences their subnuclear localization $[17,18]$. Clk/STY has been shown to interact and phosphorylate other protein kinases [19] as well as protein phosphatases [20].

Besides, clk/STY regulates its own splicing leading to two alternative spliced transcripts encoding a full-length catalytically active kinase and a truncated form lacking the kinase domain and incapable of phosphorylation $[4,13]$. When clk/STY is overexpressed in cultured cells, the kinase together with SR proteins is homogeneously localized throughout the nucleus. When the truncated form is 
overexpressed, however, both clk/STY and SR products concentrate in storage compartments known as "nuclear speckles" [10, 13, 17, 21, 22].

Three other clk proteins have been described in mammals: clk2, clk3 and clk4 [8, 10, 23, 24]. As in the case of clk/STY, the clk2, 3 and 4 kinases also show alternative splicing and the exon/intron boundaries of the originally described "exon B" [4] are conserved $[8,10]$. Inclusion of the "B-like exon" in clk2, 3 and 4 produces a full-length catalytically active protein. On the contrary, the lack of "B-like exon" introduces a premature stop codon giving rise to a protein missing the kinase domain. Like $\mathrm{clk} / \mathrm{STY}$, all variants encode autophosphorylating proteins that can phosphorylate and colocalize with SR proteins [10, 25-27].

Regulation of the phosphorylation status of SR proteins by clks has been shown to exert specificity. Members of the clk family selectively regulate exon 10 usage of the tau microtubule-associated protein, being clk2 the kinase showing the strongest effect [28]. Kic1 kinase, an orthologue of clk/STY in Schizosaccharomyces pombe, was also suggested to have preferential targets [11] and only the inactive isoform of clk4 interacts with an SR-richrelated protein [29]. It was recently reported that the ability of clk/STY to recognize different SR proteins is influenced by the extent and nature of autophosphorylation [30].

The biological role of clk/STY is not yet fully characterized. Members of the LAMMER subfamily are implicated in development and cell differentiation. Clk/STY triggers neuronal differentiation in PC12 cells [31]. Expression of stable transfectants mimics activation of the growth factor-dependent kinase cascades and results in a neuronal phenotype. Clk/STY is also developmentally regulated in P19 EC stem cells treated either with retinoic acid to provoke differentiation into neural lineage or DMSO for cardiac and skeletal muscle lineage [2]. In Drosophila, mutations in the LAMMER kinase Doa alter sexual differentiation and activity of the Doa locus is required for development of embryonic tissues [14, 32]. It was recently shown that the pk12 LAMMER kinase also modulates development and gene expression in tobacco cells [16].

Here we showed that the expression of all members of the clk family is modulated during murine erythroleukemia (MEL) cell differentiation. While screening a cDNA library searching for genes involved in the response to HMBA (hexamethylene bisacetamide) in this cell line we found clk/STY as a potential candidate. We found that clk/STY as well as clk 2, 3 and 4 was up-regulated during induced differentiation. Transcripts coding for the fulllength or the truncated form lacking the kinase domain were responsible for the overall expression increase. The ratio of these two transcripts, however, changed along differentiation. After commitment, when most cells were already differentiated, the truncated form of clk/STY exceeded that one including the "B-like exon". When clk/ STY was overexpressed, a bias toward the truncated form was still observed at latter stages of differentiation.

\section{MATERIALS AND METHODS \\ Cell culture}

MEL-DS 19 cells were maintained in Dulbecco's modified Eagle's (DME) medium supplemented with $10 \%$ fetal bovine serum (FBS) and $100 \mathrm{units} / \mathrm{ml}$ of penicillium and streptomycin (Gibco), in a humidified incubator at $37^{\circ} \mathrm{C}$ in the presence of $5 \% \mathrm{CO}_{2}$. Differentiation of MEL cells was induced by exposing logarithmically growing cultures to $5 \mathrm{mM}$ HMBA. MEL-R (MEL resistant) was established by successive passes in the presence of the inducer and was routinely culture in DME with $5 \mathrm{mM}$ HMBA. Hemoglobinized cells were monitored by determining the proportion of benzidine-staining positive cells $(\mathrm{B}+)$ in the culture.

\section{Isolation of RNA and Northern analysis}

Total RNA was isolated from $1 \times 10^{7}$ growing cells using the Trizol reagent as described by the supplier (Gibco BRL). RNA samples (15 $\mu \mathrm{g}$ ) were electrophoresed through formaldehyde-agarose gels and transferred to Zeta-probe blotting membranes (Bio-Rad) in $10 \times \mathrm{SSC}$.

\section{Radioactive hybridization}

Prehybridization was carried out in $50 \%$ Formamide, $50 \mathrm{mM}$ $\mathrm{NaH}_{2} \mathrm{PO}_{4} \mathrm{pH} 6.8,0.1 \%$ SDS, $5 \times \mathrm{SSC}, 0.1 \%$ Sodium Pyrophosphate, $5 \times$ Denhardt solution, and $300 \mu \mathrm{g} / \mathrm{ml}$ sonicated salmon sperm DNA at $42^{\circ} \mathrm{C}$. After $3-4 \mathrm{~h}, 1 \times 10^{7} \mathrm{cpm} / \mathrm{ml}$ of DNA probe labelled with $32^{\mathrm{P}}-$ $\mathrm{dCTP}$ by random priming was added and incubated at $42^{\circ} \mathrm{C}$ overnight. The membranes were washed successively in $2 \times \mathrm{SSC} / 0.1 \% \mathrm{SDS}$, $1 \times \mathrm{SSC} / 0.1 \% \mathrm{SDS}, 0.5 \times \mathrm{SSC} / 0.1 \% \mathrm{SDS}, 0.1 \times \mathrm{SSC} / 0.1 \% \mathrm{SDS}$ at room temperature and twice in $0.1 \times \mathrm{SSC} / 0.1 \% \mathrm{SDS}$ at $65^{\circ} \mathrm{C}$.

\section{Non-radioactive hybridization}

Prehybridization was carried out in $0.5 \mathrm{M} \mathrm{NaH}_{2} \mathrm{PO}_{4} \mathrm{pH} 7.2,7 \%$ SDS, $1 \%$ BSA and $300 \mu \mathrm{g} / \mathrm{ml}$ sonicated salmon sperm DNA, at $65^{\circ} \mathrm{C}$. After 3-4 h, DNA probe labelled with Random Primer Fluorescein kit (NEN Life Sciences Products) was added and incubated at $65^{\circ} \mathrm{C}$ overnight. The membranes were washed twice in $40 \mathrm{mM} \mathrm{NaH}_{2} \mathrm{PO}_{4}$, $1 \% \mathrm{SDS}$ at room temperature, for $10 \mathrm{~min}$, followed by $30 \mathrm{~min}$ at $65^{\circ} \mathrm{C}$ in the same solution. Detection was performed with an antifluoresceinAP conjugate and CDP-Star (NEN) according to the instructions provided by the manufacturer.

\section{Western blot analysis}

Transfected MEL cells $\left(1 \times 10^{7}\right)$ were pelleted, washed twice in cold PBS and lyzed in RIPA buffer (150 mM NaCl, $1 \% \mathrm{NP}-40,0.1 \%$ $\mathrm{SDS}, 50 \mathrm{mM}$ Tris- $\mathrm{HCl} \mathrm{pH} 8.0,1 \%$ Sodium deoxycholate) at $4^{\circ} \mathrm{C}$, followed by sonication. Lysates were concentrated with Microconamicon YM-3 (Millipore) and equal amount of protein (50 $\mu \mathrm{g}$ of total protein) were resolved by $10 \%$ SDS-polyacrylamide gel electrophoresis. Proteins were electrotransferred to IMMUN-BLOT PVDF membranes (Bio-Rad), blocked with 5\% nonfat milk in TBST buffer (20 mM Tris pH 7.6, $137 \mathrm{mM} \mathrm{NaCl}, 0.1 \%$ Tween-20) for 1 $\mathrm{h}$ at room temperature and incubated with a rat monoclonal anti-HA 
antibody (1:500, Roche). The secondary antibody reaction was performed with horseradish peroxidase-conjugated rabbit anti-rat antibody $(1: 1000$, DAKO). HRP activity was detected using the SuperSignalWest Pico chemiluminescent substrate (Pierce).

\section{cDNA cloning and RT-PCR analysis}

$\mathrm{Clk} / \mathrm{STY}$ complete cDNA was amplified by PCR from the GST/ Clk plasmid (a gift from Dr. John BELL) using the primers forward 5'-CGC GGA TCC ATG AGA CAT TCA AAG AGA ACT-3' and reverse 5'-ATA GTT TAG CGG CCG CCG TAT GCT TTT TAA GTG-3'. Clk 2, 3 and 4 complete cDNAs were obtained by RT-PCR using forward and reverse primers described in [10]. PCR products were gel purified and cloned into the pSTBlue-1 plasmid (Novagen). For RT-PCR reactions 5-15 $\mu \mathrm{g}$ of total RNA extracted from MEL cells was reverse-transcribed at $42^{\circ} \mathrm{C}$ for $45 \mathrm{~min}$ in the presence of $2.25 \mu \mathrm{M}$ oligo-dT (Roche), $500 \mu \mathrm{M}$ each nucleotide, 10 units RNasin and 5 units M-MLV reverse transcriptase (USB). PCR reactions were performed using $200 \mu \mathrm{M}$ each nucleotide, $0.5 \mu \mathrm{M}$ sense and antisense primers and 5 units of Ampli-Taq polymerase (Perkin Elmer) in a $50 \mu \mathrm{l}$ total volume. PCR conditions were: $94^{\circ} \mathrm{C}$ for $1 \mathrm{~min}$, $55^{\circ} \mathrm{C}$ for $1 \mathrm{~min}$, and $72^{\circ} \mathrm{C}$ for $2 \mathrm{~min}, 30$ cycles. Exon exclusion/inclusion in clk/STY, 2, 3 and 4 was analyze by PCR amplification using the following primers: clk/STY forward 5'-ATG AGA CAT TCA AAG AGA ACT-3', clk/STY reverse 5'-TCC ACC ACT TTT CCG AAA GCA-3', clk2 forward 5'-TCC CCC GGG ATG CCC CAT CCC CGAAGG TAC CA-3', clk2 reverse 5'-CTG CAC AAC TCG GCC CGA ATG-3', clk3 forward 5'-ATG CAT CAC TGT AAG CGA TAC CG-3', clk3 reverse 5'-AAG CAC TCC ACC ACC TTG CCA AA-3' and clk4 forward 5'-CGG AAT TCA TGC GGC ATT CCA AAC GAA CTC-3', clk4 reverse 5'-GCA CTC TAC AAC TTT GCC AAA GGC-3'. PCR conditions were $94^{\circ} \mathrm{C}$ for $30 \mathrm{sec}$, $55^{\circ} \mathrm{C}$ for $1 \mathrm{~min}, 72^{\circ} \mathrm{C}$ for $1 \mathrm{~min}, 30$ cycles for clk 1,2 and $3 ; 94^{\circ} \mathrm{C}$ for $30 \mathrm{sec}, 65^{\circ} \mathrm{C}$ for $1 \mathrm{~min}, 72^{\circ} \mathrm{C}$ for $1 \mathrm{~min}, 30$ cycles for clk4. Glyceraldehyde phosphate dehydrogenase (GAPDH) used as a control was amplified with the primers: forward 5'-ACC ACA GTC CAT GCC ATC AC-3' and reverse 5'-TCC ACC ACC CTG TTG CTG TA-3', for 20 cycles.

\section{Construction of clk/STY-expression vectors and cell trans- fection}

$\mathrm{Clk} / \mathrm{STY}$ cDNA was amplified by PCR from the GST/STY plasmid (a gift from J. BELL) using BamH1 and NotI tagged primers: forward 5'-CGC GGA TCC ATG AGA CAT TCA AAG AGA ACT3' and reverse 5'-ATA GTT TAG CGG CCG CCG TAT GCT TTT TAA GTG-3'. Clk/STYtr cDNA was obtained by RT-PCR from MEL cells. PCR reactions were performed using forward 5'-ATG AGA CAT TCA AAG AGA ACT-3' and reverse 5'-ATA GTT TAG CGG CCG CCG TAT GCT TTT TAA GTG-3' primers. PCR products were cloned into the pSTBlue-1 vector (Novagen) and selected

by colony PCR followed by sequencing confirmation. Clk/STYtr

cDNA was then amplified using BamH1 and NotI tagged primers: forward 5'-CGC GGA TCC ATG AGA CAT TCA AAG AGA ACT3' and reverse 5'-ATA GTT TAG CGG CCG CAA GTA TCA ACA ATT TCA-3'. Both clk/STY and clk/STY ${ }^{\text {tr }}$ PCR products were introduced into the pEBBpuro-HA expression vector, a gift from G. CHENG, UCLA [33]. For stable transfections, $3 \mu \mathrm{g}$ of each pEBBpuroclk1-HA and pEBBpuroclk ${ }^{\text {tr }}$-HA were introduced into MEL cells using lipofectine (Gibco) as previously described [34]. Individual clones obtained by limited dilution were selected and main- tained in medium containing $5 \mu \mathrm{g} / \mathrm{ml}$ puromycin. Clones were expanded and analyzed by Western blot for expression of the clk constructs. For transient experiments cells were transfected with the GFP-C1 expression vector (Clontech) fused to clk/STY or clk/STYtr. After $24 \mathrm{~h}$ cells were washed in cold PBS and processed for immunofluorescence.

\section{RESULTS} Expression of clk/STY, clk2, clk3 and clk4 in HMBA-
treated murine erythroleukemia cells

We identified clk/STY while screening MEL cDNA libraries constructed from poly A+ RNA isolated from MEL cells grown in the presence of HMBA [34, 35]. After two rounds of differential hybridization with complex probes derived from uninduced and HMBA-induced cells and Northern analysis, a 900 bp clone was identified as an upregulated cDNA during differentiation. When compared to the Genbank/EMBL database we found that the DNA sequence corresponded to a partial cDNA 95\% homologous to the previously described clk/STY [2]. We next examined the expression of clk/STY throughout HMBAinduced differentiation. Fig. 1A shows a Northern blot of total RNAs isolated from untreated cells or cells treated from 1 up to $120 \mathrm{~h}$ with $5 \mathrm{mM}$ HMBA. We confirmed that the percentage of benzidine positive cells $(\mathrm{B}+)$ in the culture exceeded $90 \%$ after five days of treatment. Using the full-length cDNA as a probe, two transcripts of about 3.2 and $1.8 \mathrm{~kb}$ were detected. This result agreed with previous observations made in several cell lines and tissues [1, $2,4,10]$. The $3.2 \mathrm{~kb}$ band corresponded to an incompletely processed transcript that accumulated in the nucleus [4]. The $1.8 \mathrm{~kb}$ band exhibited a diffuse pattern probably due to co-migration of two alternative spliced forms [4]. In untreated MEL cells we observed low levels of both the 3.2 and the $1.8 \mathrm{~kb}$ transcripts. After exposure of the cells to HMBA there was a slight decline of expression at precommitment stages that lasted 4-6 h. Afterward, the level of clk/STY mRNA increased steadily reaching its highest value after $120 \mathrm{~h}$ of culture in the presence of the inducer (Fig. 1A). Similar results were observed for clk2, clk3 and clk4 cDNA probes in Northern analyses of untreated and differentiated cells (Fig. 1B). All three genes were expressed at low levels in MEL cells $(0 \mathrm{~h})$ but their expression became conspicuous after $120 \mathrm{~h}$ in the presence of HMBA. Expression of clk4 was very low in both uninduced and differentiated cells, and only a weak signal was detected after increasing the amount of total RNA in the blot.

\section{Expression of alternatively spliced forms throughout MEL differentiation}

$\mathrm{Clk} / \mathrm{STY}$ is alternatively spliced to produce a $1.8 \mathrm{~kb}$ and 
A

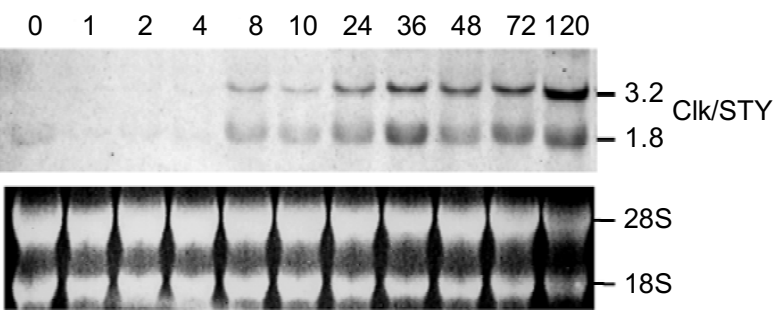

B

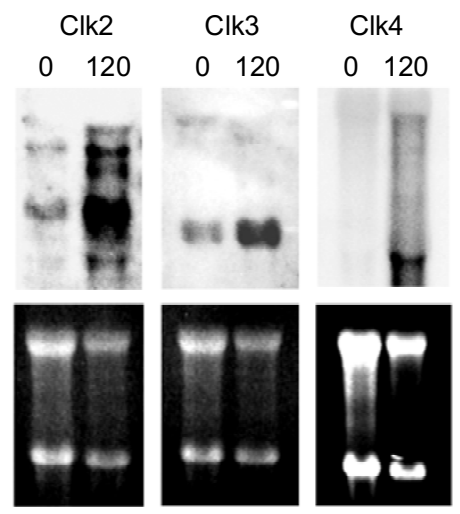

Fig. $1 \mathrm{Clk} / \mathrm{STY}$, clk2, clk3 and clk4 expression during HMBA-induced MEL cell differentiation. (A) Fifteen micrograms of total RNA isolated from untreated $(0)$ or treated with $5 \mathrm{mM}$ HMBA for 1 up to $120 \mathrm{~h}$ were analyzed by Northern blot hybridization. A fluoresceinlabelled fragment corresponding to the full-length clk/STY cDNA was used as a probe. (B) Fifteen micrograms of total RNA for clk2 and clk3 and twenty five micrograms for clk4 isolated from untreated $(0)$ or treated with $5 \mathrm{mM}$ HMBAduring $120 \mathrm{~h}$ were analyzed by Northern blot. Radioactive probes corresponded to complete cDNA fragments from clk2, clk3 and clk4, respectively. Ethidium bromide staining was used as a control of integrity and equal loading of the samples in A and B.

a $1.7 \mathrm{~kb}$ transcripts that code for a complete active kinase and a truncated form, respectively [4]. Differences between the two spliced forms reside in the inclusion/exclusion of exon 4 (originally described as "exon B" [4] out of 13 exons present in the clk/STY genomic sequence (data obtained from the Mouse Genome Sequencing Consortium [36], http://www.ensembl.org/). Clk2, clk3 and clk4 follow a similar splicing mechanism [10] with exon 4 (out of 13 exons) inclusion/exclusion at analogous locations. Based on the observation that clk/STY as well as clk2, 3 and 4 isoforms are up-regulated along MEL differentiation, we investigated whether or not both the $1.8 \mathrm{~kb}$ and the 1.7 $\mathrm{kb}$ transcripts followed the same pattern. RT-PCR reactions were performed using primers that contained the ATG initiation codon at the $5^{\prime}$ end and primers located after exon 4 for the 3 ' end of the amplified fragments for each of the isoforms (Fig. 2). RT-PCR reactions were carried out from uninduced MEL cells and cells treated for $120 \mathrm{~h}$ with HMBA (Fig. 3A). The two predicted bands, products of alternative splicing were clearly observed. The ratio between the two bands, however, was dramatically altered. The 527 bp upper band that included exon $4(+)$ prevailed over the truncated form (-) in untreated MEL cells but the situation was the reverse after differentiation. When a similar experiment was performed with an MEL resistant clone that does not differentiate when constantly exposed to HMBA, prevalence of exon 4 inclusion was observed (Fig. 3A). This indicated that inclusion/exclusion of exon 4 is not affected by HMBA but directly correlates with cell differentiation. RT-PCR reactions were also performed for each of the clks from uninduced cells and cells treated from 6 up to $120 \mathrm{~h}$ with HMBA (Fig. 3B). The two expected bands were observed in all clks but the ratio in each case varied between isoforms and throughout

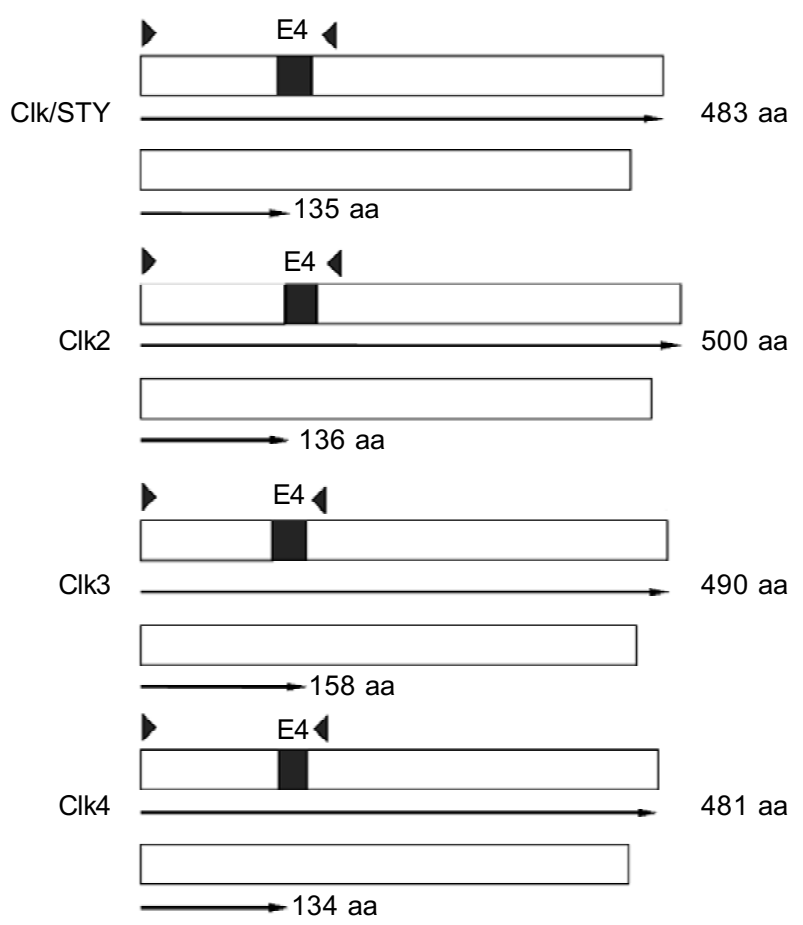

Fig. 2 Schematic representation of clk/STY, clk2, clk3 and clk4 cDNAs. Each segment is drawn in scale and includes the region between the ATG initiation codon and the TGA stop codon of the full length protein. Black areas inside the segments correspond to exon 4 (E4). Arrows below each segment correspond to the full-length and truncated protein, respectively, resulting from alternative splicing of exon 4. Amino acid values for full-length and putative truncated protein are indicated. Arrowheads above each segment indicate the position of the primers used in RT-PCR reactions to amplify both the complete and the truncated isoforms. 
A

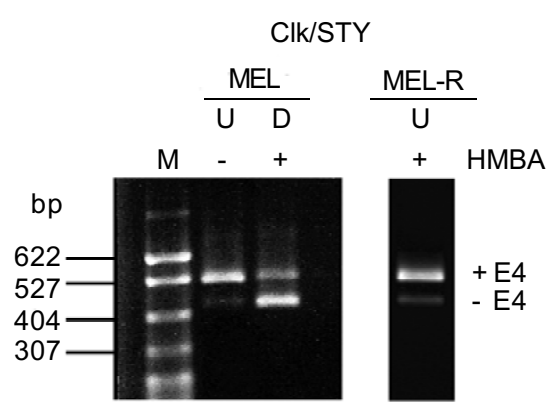

B

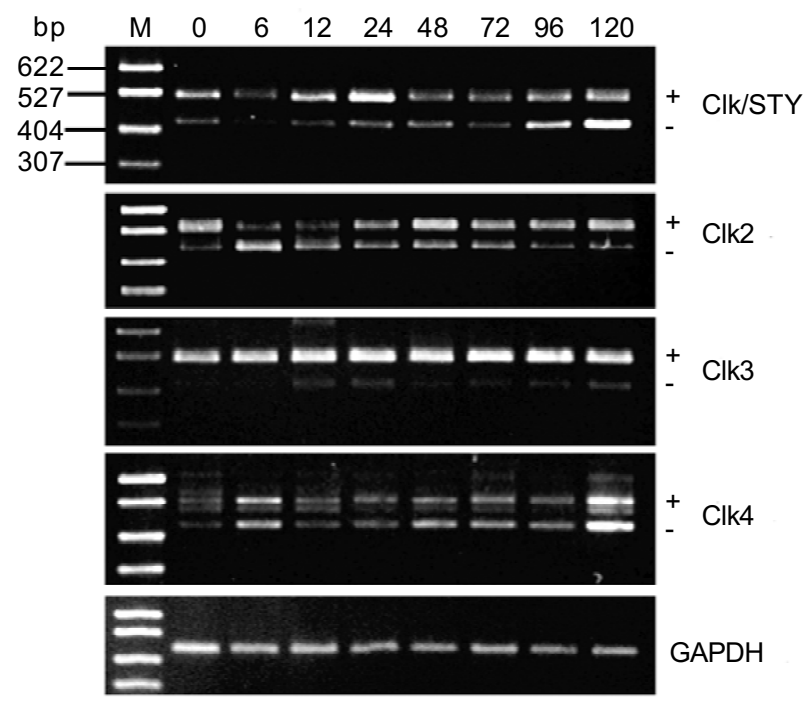

Fig. 3 RT-PCR analysis of clks transcripts during MEL cell differentiation. (A) Total RNA from undifferentiated (U), differentiated (D) MEL and from MEL-R cells were reverse transcribed and amplified by PCR using 5' primers that include the ATG-initiation codon and 3' end primers flanking exon 4 (see Fig. 2). PCR products were normalized to GAPDH, electrophoresed on a $1.8 \%$ agarose gel and stained with ethidium bromide. Upper and lower bands correspond to transcripts that include $(+)$ or exclude (-) exon 4. M: marker. (B) Total RNA from undifferentiated MEL cells (0) or cells treated with $5 \mathrm{mM}$ HMBA from 6 up to $120 \mathrm{~h}$ were reverse transcribed, amplified and processed as in (A). M: marker.

differentiation. Again for clk/STY the upper band prevailed over the lower band in undifferentiated cells. This situation persisted after exposure of the cells to HMBA until commitment and early differentiation. $96 \mathrm{~h}$ later we observed the bias toward the truncated form that became more conspicuous at $120 \mathrm{~h}$. A high percentage of exon exclusion was also observed for clk4 although in this case the ratio between isoforms remained similar at every timepoint. There was a moderate increase of expression for both isoforms at $6 \mathrm{~h}$. Additional bands were also amplified in this case even at very stringent PCR conditions (Fig. 3B). These extra bands corresponded to a different spliced product that contained an additional putative exon (unpublished results). Clk2 and clk3 amplification exhibited a prevalence of the band including exon 4 with an unforeseen exception at pre-commitment stages ( 6 and $12 \mathrm{~h}$ ) in clk2. The alternative spliced transcript lacking exon 4 was minoritary in clk3 throughout differentiation

\section{A}

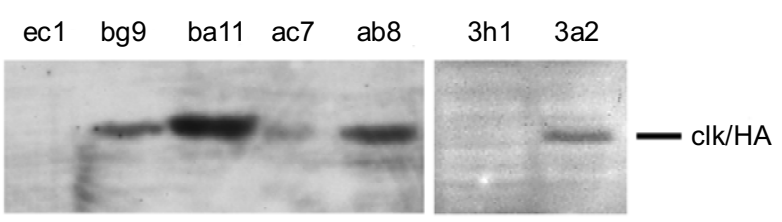

B

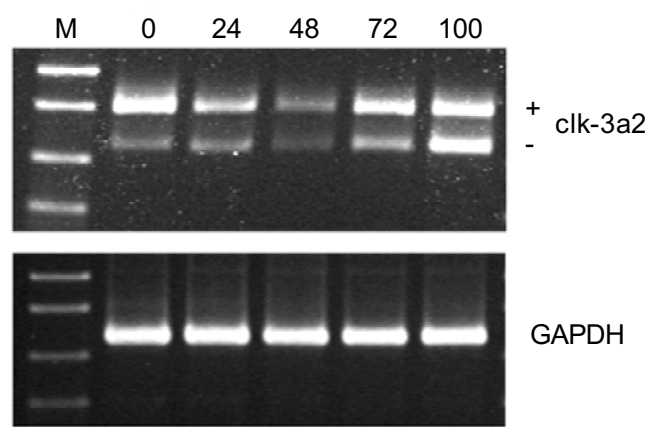

C

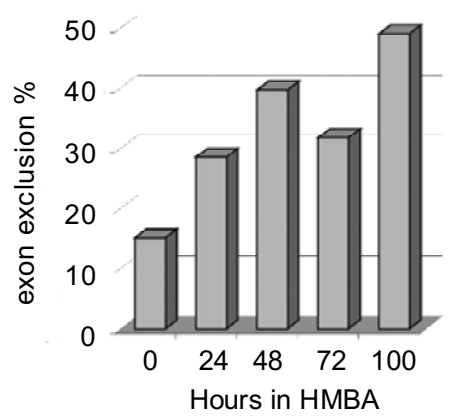

Fig. 4 Characterization of clk/STY MEL cell transfectants. (A) MEL cell clones were selected in puromycin containing media. Total cellular protein extracts were prepared and the level of clk/STY-HA fusion protein was determined by Western blot using a HA-antibody. Clone numbers appear above each lane. (B) Total RNA from undifferentiated MEL clone $3 \mathrm{a} 2(0)$ or cells treated with $5 \mathrm{mM}$ HMBA for $24,48,72$ or $100 \mathrm{~h}$ were reverse transcribed and amplified by PCR using 5' primers that includes the ATG-initiation codon and 3 ' end primers flanking exon 4 (see Fig. 2). PCR products were normalized to GAPDH, electrophoresed on a $1.8 \%$ agarose gel and stained with ethidium bromide. Upper and lower bands correspond to transcripts that include (+) or exclude (-) exon 4. M: marker. (C) Percentage of exon exclusion in the $3 \mathrm{a} 2$ transfectant. 
(Fig. 3B). In summary, we showed that both the complete and the truncated isoforms of all clks were expressed during differentiation. A switch in prevalence favoring the truncated form, however, was significant for clk/STY.

\section{Forced expression of clk/STY enhances exon exclusion}

RT-PCR experiments showed that clk/STY exon exclusion occurred primarily during latter stages of MEL differentiation. This observation suggests that the ratio between the complete and the truncated clk/STY isoforms could be regulated during the process. To test whether an unbalance of this ratio affects differentiation, clk/STY cDNA fused in frame with a HA-tag was cloned into the pEBB mammalian expression vector and used to generate stable MEL transfectants. Clones growing in a selective medium were checked for proper expression by Western blotting (Fig. 4A). Selected clones were then induced to differentiate with HMBA and we counted the percentage of benzidine positive $(\mathrm{B}+)$ cells. No significant differences were appreciated between mock and clk/STY stable transfectants (data not shown). Next we carried out RTPCR experiments to look for the ratio of clk/STY complete and truncated isoforms. Fig. 4B shows the results obtained with clone $3 \mathrm{a} 2$. As expected for constitutive expression, in untreated cells the clk/STY complete cDNA exceeded the truncated form in a significant manner and consequently the percentage of exon exclusion remained low (Fig. 4B and C). As differentiation proceeded, however, the ratio changed favoring the truncated isoforms. At latter stages the percentage of exon exclusion reached values close to $50 \%$, similar to those observed for control MEL cells (Fig. 3A and B). These results strongly suggest a tight regulation between clk isoforms. Moreover, this regulation seemed to favor an excess of the truncated form toward the end of the differentiation process. Stable transfectants were obtained also for the clk/STY-truncated construction. In that case, however, no $\mathrm{clk}^{\text {tr }}$-HA chimeric protein was detected. We performed 3 independent transfections and obtained a total of 113 clones from which approximately a third was analyzed by Western blotting. Some of the transfectants were randomly chosen to perform RT-PCR reactions and although significant amounts of the mRNA truncated isoforms were present in some of the clones, no protein was detected.

\section{DISCUSSION}

SR proteins are essential components of the splicing machinery that exert its function through phosphorylation/dephosphorylation cycles [37,38]. The clks LAMMER proteins are among those kinases capable to phosphorylate SR proteins [17]. Here we showed that the expression of clk/STY as well as other members of the clk family was modulated throughout HMBA-induced differentiation in MEL cells (Fig. 1A and B). Very low levels of clks expression are characteristic of untreated MEL cells, particularly for clk/STY. Almost immediately after the cells were exposed to the inducer there was a further decline of clks mRNA levels. This is a recurrent pattern during MEL early differentiation stages that was already described for a number of genes such as c-myc, c-myb, PU.1, GATA, EKLF, Hsp70, ribosomal S5 and Ran [34 and references therein]. This effect is probably a consequence of the prolonged G1 phase that takes place after exposure to the inducer causing a temporal transcription delay [39]. Moreover, reprogramming MEL cells into terminal differentiation requires also the inhibition of specific cyclin-dependent kinases that is restricted to the G1 phase of the cell cycle $[40,41]$. After commitment, when the cells irreversibly resume their differentiation program [42], clk/STY mRNA levels steadily increased (Fig. 1A). Similar results were observed for P19 stem cells treated with retinoic acid (RA) to differentiate into neurons and astroglia [2]. In RA-treated cultures there is an overall increase in the level of expression of clk/STY. However, when the same cells are treated with DMSO to produce cardiac and skeletal muscle cells, clk/STY transcripts decrease with time. These findings are consistent with the high level of expression observed in neural and hematopoietic tissues and cell lines $[1-3,10]$. Taken together, the results obtained with P19 and MEL cells suggest that modulation of clk/STY expression during cell differentiation does not follow a unique pattern but is specific for different tissues and cell lines.

Here we confirmed that the clk/STY mRNA level increase observed throughout MEL differentiation did not correspond to an equal accumulation of the two alternative isoforms. The $1.8 \mathrm{~kb}$ transcript encoding the complete active kinase predominated in untreated cells and early committed stages. There was a shift toward the isoform encoding the truncated protein, however, at latter stages of differentiation (Fig. 3A and B). This switch was not observed in MEL-R cells. This observation indicated that prevalence of the truncated form was related to differentiation itself and not to the presence of HMBA. These results suggest a regulation based on the balance between the two isoforms. Duncan and co-workers showed that clk/STY and clk-truncated proteins influence their own splicing in a different manner [13] and support the hypothesis that the truncated protein might be a natural antagonist of clk/STY activity.

The results we obtained using stable transfectants overexpressing clk/STY strengthened the idea of a competitive regulation between the two isoforms. Constitutive exogenous expression of clk/STY would trigger exon inclusion in untreated MEL clones. As differentiation 
resumed, a pressure favoring the truncated isoforms would build-up in a percentage similar to exon exclusion in wild type cells (Fig. 4B and C).

Unfortunately, we failed to detect the truncated protein following selection of stable transfectants that constitutively express the exon 4-exclusion isoform. Menegay and co-workers generated polyclonal antibodies against clk/ STY N-terminal region [43] and observed abundant full length, but not truncated clk/STY protein in PC12 cell lysates. On the other hand, clk/STY full length and truncated proteins were readily detected using epitope-tagging expression vectors $[4,13,26]$. These vectors include clk/ STY tagged with a six-repeat Myc epitope increasing the molecular mass of the proteins by approximately $10 \mathrm{Kda}$ [4]. We can speculate that the clk/STY-truncated protein is very unstable or even not viable. The truncated form might readily form and become stabilized, however, when fused to other sequences.

Alternative splicing is emerging as an essential mechanism for the regulation of gene expression [44, 45]. Expansion of the genome capacity by producing multiple functional proteins is the most recognizable advantage. However, alternative splicing can also produced isoforms that would be recognized as targets for degradation. In fact, one-third of alternative transcripts examined from known human genes are potential targets for nonsensemediated mRNA decay (NMD) [46]. Clk/STY, as well as clk2, 3 and 4, are all candidates for NMD. In all these cases exclusion of exon 4 causes a frameshift resulting in the introduction of premature stop codons. However, NMD should lead to rapid mRNA degradation; instead we detected an accumulation of the truncated clk/STY mRNA. We speculate that either NMD proceeds in a slow fashion or there is another mechanism involved in the processing of mRNA. Autoregulation via alternative splicing and NMD has been described for other members of the splicing machinery such as PTB [47], SC35 [48], TIA and TIAR [49], Srp20 [50], ADAR2 [51] and hnRNPA1 [52]. These observations led Wollerton and co-workers to propose a common mechanism for gene expression control [47]. Exon 4 in clk/STY is flanked by introns containing several cisacting sequences optimal for the PTB protein binding (data not shown). PTB is recognized to act as a splicing repressor and is a candidate to promote exon exclusion in clks.

Regulation of alternative pre-mRNA splicing during erythroid differentiation has been widely documented [53]. Special attention is given to the alternative splicing of protein 4.1, a structural component of the red blood cell cytoskeleton [54-56]. It was suggested that regulation of protein 4.1 during erythroid maturation is a major and essential event related to structural and functional differences between proerythroblasts and mature red cells [55]. Also,
Lallena and co-workers demonstrated that protein 4.1 associates with factors involved in pre-mRNA splicing and that 4.1 overexpression causes redistribution of the SRprotein SC35 [57].

\section{ACKNOWLEDGEMENTS}

We thank Drs J.C. BELL (Otawa Regional Cancer Center) and T. PAWSON (S. Lunenfeld Research Institute, Toronto) for providing the clk/STY constructs and Dr G. CHENG (Molecular Biology Institute, UCLA) for the pEBBHA expression vector. We are also grateful to M.L. MARTÍNEZ and P. ROBLES for technical assistant. This work was supported by grants 08.1/0067.1/2001.1 from the Comunidad de Madrid (CAM) and grant SAF20011740 from the Spanish Ministerio de Ciencia y Tecnología. MJFN is recipient of a graduate fellowship from the Comunidad de Madrid (CAM).

Received, Mar 24, 2005

Revised, June 7, 2005

Accepted, June 28, 2005

\section{REFERENCES}

1 Ben-David Y, Letwin K, Tannock L, Bernstein A, Pawson T. A mammalian protein kinase with potential for serine/threonine phosphorylation is related to cell cycle regulators. EMBO J 1991; 10:317-25.

2 Howell B, Afar D, Lew J, et al. STY, a tyrosinephosphorylating enzyme with sequence homology to serine/threonine kinases. Mol Cell Biol 1991; 11:568-72.

3 Johnson K, Smith K. Molecular cloning of a novel human cdc2/ CDC28-like protein kinase. J Biol Chem 1991; 266:3402-7.

4 Duncan P, Howell B, Marius R, et al. Alternative splicing of STY, a nuclear dual specificity kinase. J Biol Chem 1995; 270: 21524-31.

5 Yun B, Farkas R, Lee K, Rabinow L. The Doa locus encodes a member of a new protein kinase family and is essential for eye and embryonic development in Drosophila melanogaster. Genes Dev 1994; 8:1160-73.

6 Padmanabha R, Gehrung S, Snyder M. The KNS1 gene of Saccharomyces cerevisiae encodes a nonessential protein kinase homologue that is distantly related to members of the CDC28/ cdc2 gene family. Mol Gen Genet 1991; 229:1-9.

7 Bender J, Fink GR. AFC1, a LAMMER kinase from Arabidopsis thaliana, activates STE12-dependent processes in yeast. Proc Natl Acad Sci U S A 1994; 91:12105-9.

8 Hanes J, von der Kammer H, Klaudiny J, Scheit KH. Characterization by cDNA cloning of two new human protein kinases. Evidence by sequence comparison of a new family of mammalian protein kinases. J Mol Biol 1994; 244:665-72.

9 Sessa G, Raz V, Savaldi S, Fluhr R. PK12, a plant dual-specificity protein kinase of the LAMMER family, is regulated by the hormone ethylene. Plant Cell 1996; 8:2223-34.

10 Nayler O, Stamm S, Ullrich A. Characterization and comparison of four serine- and argininerich (SR) protein kinases. Biochem J 1997; 326:693-700. 
11 Tang ZH, Mandel LL, Yean SL, et al. The Kic1 kinase of Schizosaccharomyces pombe is a CLK/STY orthologue that regulates cellcell separation. Exp Cell Res 2003; 283:101-15.

12 Taylor SS, Knighton DR, Zheng J, Ten Eyck LF, Sowadski JM. Structural framework for the protein kinase family. Annu Rev Cell Biol 1992; 8:429-62.

13 Duncan PI, Stojdl DF, Marius RM, Bell JC. In vivo regulation of alternative pre-mRNA splicing by the Clk1 protein kinase. Mol Cell Biol 1997; 17:5996-6001.

14 Du C, McGuffin ME, Dauwalder B, Rabinow L, Mattox W. Protein phosphorylation plays an essential role in the regulation of alternative splicing and sex determination in Drosophila. Mol Cell 1998; 2:741-50.

15 Savaldi-Goldstein S, Sessa G, Fluhr R. The ethylene-inducible PK12 kinase mediates the phosphorylation of SR splicing factors. Plant J 2000; 21:91-6.

16 Savaldi-Goldstein S, Aviv D, Davydov O, Fluhr R. Alternative splicing modulation by a LAMMER kinase impinges on developmental and transcriptome expression. Plant Cell 2003; 15: 926-38.

17 Colwill K, Pawson T, Andrews B, et al. The Clk/Sty protein kinase phosphorylates SR splicing factors and regulates their intranuclear distribution. EMBO J 1996; 15:265-75.

18 Prasad J, Colwill K, Pawson T, Manley JL. The protein kinase $\mathrm{Clk} /$ Sty directly modulates SR protein activity: Both hyperand hypophosphorylation inhibit splicing. Mol Cell Biol 1999; 19:6991-7000.

19 Kojima T, Zama T, Wada K, Onogi H, Hagiwara M. Cloning of human PRP4 reveals interaction with Clk1. J Biol Chem 2001; 276:32247-56.

20 Moeslein FM, Myers MP, Landreth GE. The CLK family kinases, CLK1 and CLK2, phosphorylate and activate the tyrosine phosphatase, PTP-1B. J Biol Chem 1999; 274:26697704.

21 Colwill K, Feng LL, Yeakley JM, et al. SRPK1 and Clk/Sty protein kinases show distinct substrate specificities for serine/ arginine-rich splicing factors. J Biol Chem 1996; 271:24569-75.

22 Sacco-Bubulya P, Spector DL. Disassembly of interchromatin granule clusters alters the coordination of transcription and premRNA splicing. J Cell Biol 2002; 156:425-36.

23 Becker W, Kentrup H, Heukelbach J, Joost HG. cDNA cloning and characterization of rat clk3, a LAMMER kinase predominately expressed in testis. Biochem Biophys Acta 1996; 1312: 63-7.

24 Schultz J, Jones T, Bork P, et al. Molecular characterization of a cDNA encoding functional human CLK4 kinase and localization to chromosome 4q35. Genomics 2001; 71:368-70.

25 Lee K, Du C, Horn M, Rabinow L. Activity and autophosphorylation of LAMMER protein kinases. J Biol Chem 1996; 271: 27299-303.

26 Duncan PI, Stojdl DF, Marius RM, Scheit KH, Bell JC. The $\mathrm{Clk} 2$ and $\mathrm{Clk} 3$ dualspecificity protein kinases regulate the intranuclear distribution of SR proteins and influence pre-mRNA splicing. Exp Cell Res 1998; 241:300-8.

27 Nayler O, Schnorrer F, Stamm S, Ullrich A. The cellular localization of the murine serine/arginine-rich protein kinase CLK2 is regulated by serine 141 autophosphorylation. J Biol Chem 1998; 273:34341-8.

28 Hartmann AM, Rujescu D, Giannakouros T, et al. Regulation of alternative splicing of human tau exon 10 by phosphorylation of splicing factors. Mol Cell Neurosci 2001; 18:80-90.

29 Katsu R, Onogi H, Wada K, Kawaguchi Y, Hagiwara M. Novel SR-rich-related protein clasp specifically interacts with inactivated $\mathrm{Clk} 4$ and induces the exon EB inclusion of Clk. J Biol Chem 2002; 277:44220-8.

30 Prasad J, Manley JL. Regulation and Substrate Specificity of the SR Protein Kinase Clk/Sty. Mol Cell Biol 2003; 23:4139-49.

31 Myers MP, Murphy MB, Landreth G. The dual-specificity CLK kinase induces neuronal differentiation of PC12 cells. Mol Cell Biol 1994; 14:6954-61.

32 Yun B, Lee K, Farkas R, Hitte C, Rabinow L. The LAMMER protein kinase encoded by the Doa locus of Drosophila is required in both somatic and germline cells and is expressed as both nuclear and cytoplasmic isoforms throughout development. Genetics 2000; 156:749-61.

33 Chin AI, Shu J, Shan_Shi C, et al. TANK potentiates tumor necrosis factor receptor-associated factor-mediated c-Jun N-terminal kinase/stress-activated protein kinase activation through the germinal center kinase pathway. Mol Cell Biol 1999; 19: 6665-72.

34 Vanegas N, García-Sacristán A, López-Fernández L, et al. Differential expression of Ran GTPase during HMBA-induced differentiation in murine erythroleukemia cells. Leukemia Res 2003; 27:607-15.

35 Vanegas N, Castañeda V, Santamaría D, et al. Cloning, sequencing and expression in MEL cells of cDNA encoding the mouse ribosomal protein S5. Biochem Biophys Acta 1997; 1357:1-4.

36 Waterston RH, Lindblad-Toh K, Birney E, et al. Initial sequencing and comparative analysis of the mouse genome. Nature 2002; 420:520-62.

37 Misteli T. RNA splicing: What has phosphorylation got to do with it? Curr Biol 1999; 9:R198-200.

38 Stojdl DF, Bell JC. SR protein kinases: the splice of life. Biochem Cell Biol 1999; 77:293-8.

39 Kiyokawa H, Richon VM, Venta-Perez G, Rifkind RA, Marks PA. Hexamethylenebisacetamide-induced erythroleukemia cell differentiation involves modulation of events required for cell cycle progression through G1. Proc Natl Acad Sci U S A 1993; 90:6746-50.

40 Matushansky I, Radparvar F, Skoultchi AI. Reprogramming leukemic cells to terminal differentiation by inhibiting specific cyclindependent kinases in G(1). Proc Nat Acad Sci U S A 2000; 97: 14317-22.

41 Zhu L, Skoultchi AI. Coordinating cell proliferation and differentiation. Curr Opin Genet Dev 2001; 11:91-7.

42 Marks P, Sheffery M, Rifkind R. Induction of transformed cells to terminal differentiation, and the modulation of gene expression. Cancer Res 1987; 47:659-65.

43 Menegay HJ, Myers MP, Moeslein FM, Landreth GE. Biochemical characterization and localization of the dual specificity kinase CLK1. J Cell Sci 2000; 113:3241-53.

44 Smith CW, Valcarcel J. Alternative pre-mRNA splicing: the logic of combinatorial control. Trends Biochem Sci 2000; 25:381-8.

45 Modrek B, Lee CJ. Alternative splicing in the human, mouse and rat genomes is associated with an increased frequency of exon creation and/or loss. Nat Genet 2003; 34:177-80.

46 Lewis BP, Green RE, Brenner SE. Evidence for the widespread coupling of alternative splicing and nonsense-mediated mRNA 
decay in humans. Proc Natl Acad Sci U S A 2003; 100:189-92.

47 Wollerton MC, Gooding C, Wagner EJ, Garcia-Blanco MA, Smith $\mathrm{CW}$. Autoregulation of polypyrimidine tract binding protein by alternative splicing leading to nonsense-mediated decay. Mol Cell 2004; 13:91-100.

48 Sureau A, Gattoni R, Dooghe Y, Stevenin J, Soret J. SC35 autoregulates its expression by promoting splicing events that destabilize its mRNAs. Embo J 2001; 20:1785-96.

49 Le Guiner C, Lejeune F, Galiana D, et al. TIA-1 and TIAR activate splicing of alternative exons with weak 5 ' splice sites followed by a U-rich stretch on their own pre-mRNAs. J Biol Chem 2001; 276:40638-46.

50 Jumaa H, Nielsen PJ. The splicing factor SRp20 modifies splicing of its own mRNA and ASF/SF2 antagonizes this regulation. Embo J 1997; 16:5077-85.

51 Rueter SM, Dawson TR, Emeson RB. Regulation of alternative splicing by RNA editing. Nature 1999; 399:75-80.

52 Blanchette M, Chabot B. Modulation of exon skipping by high- affinity hnRNP A1-binding sites and by intron elements that repress splice site utilization. Embo J 1999; 18:1939-52.

53 Hou VC, Conboy JG. Regulation of alternative pre-mRNA splicing during erythroid differentiation. Curr Opin Hematol 2001; 8: 74-9.

54 Baklouti F, Huang SC, Tang TK, et al. Asynchronous regulation of splicing events within protein 4.1 pre-mRNA during erythroid differentiation. Blood 1996; 87:3934-41.

55 Gascard P, Lee G, Coulombel L, et al. Characterization of multiple isoforms of protein $4.1 \mathrm{R}$ expressed during erythroid terminal differentiation. Blood 1998; 92:4404-14.

56 Parra MK, Gee SL, Koury MJ, Mohandas N, Conboy JG. Alternative 5 ' exons and differential splicing regulate expression of protein 4.1R isoforms with distinct N-termini. Blood 2003; 101: 4164-71.

57 Lallena MJ, Martínez C, Valcárcel J, Correas I. Functional association of nuclear protein 4.1 with pre-mRNA splicing factors. J Cell Sci 1998; 111:1963-71. 